\title{
Construction and Practice of Virtual Simulation Experimental Teaching Platform for Economic Management
}

\author{
Xie Hongyan \\ Comprehensive Practice Center of Economic and Management, School of Management, Harbin University of \\ Commerce, Harbin 150028, Heilongjiang, China \\ xhy0710@163.com
}

Keywords: economic management; virtual simulation; experimental teaching; platform construction

\begin{abstract}
This paper introduces the concept of virtual simulation experiment teaching and its advantages over traditional experimental teaching, and analyzes the necessity of the construction of virtual simulation experiment teaching platform. On the basis of the objectives and principles of virtual simulation experiment teaching platform construction, this paper takes the virtual enterprise experimental teaching platform of modern enterprise business operation of Harbin University of Commerce as the research object, and puts forward the construction idea of the four-stage cross-professional virtual simulation experiment teaching platform, and the application effect of the cross-professional virtual simulation experiment teaching platform of management and management is expounded. Through platform training, students will be able to improve their comprehensive execution ability and comprehensive decision-making ability in business management, cultivate students' sense of collaboration and team spirit, and enhance students' comprehensive practical ability and innovative entrepreneurship ability.
\end{abstract}

\section{Introduction}

In recent years, colleges and universities across the country are stepping up the construction of experimental teaching centers and virtual simulation experimental teaching centers. Many schools have built virtual simulation experiment teaching centers as a breakthrough in the reform of talent training mode and teaching reform. How to build and meet the construction requirements of the national-level virtual simulation experiment teaching platform is an issue facing the builders [1].

\section{Concept and Advantages of Virtual Simulation Experiment Teaching}

\subsection{Concept of Virtual Simulation Experiment Teaching}

The National Virtual Simulation Experimental Teaching Center is an important part of the construction of higher education informatization construction and experimental teaching demonstration center. It is the product of the deep integration of subject professional and information technology. It is also the development direction of experimental teaching, with emphasis on building information-based experimental teaching resources. Virtual simulation experiment teaching refers to relying on virtual reality, multimedia, human-computer interaction, database and network communication technologies to build a highly simulated virtual experimental environment and experimental objects, to achieve teaching functions that are not or difficult to complete in real experiments. Students in virtual environments carry out experiments to achieve the required cognitive and practical teaching effects.

\subsection{Advantages of Virtual Simulation Experiment Teaching}

Compared with traditional experimental teaching, the virtual simulation experiment teaching is mainly reflected in the following aspects: 
(1) It can provide sufficient and independent operation space, which is conducive to the cultivation of students' innovative ability; (2) Breaking through the limitations of time and space, enabling more students to participate in the experiment; (3) It can simulate the actual difficulty of implementation or high implementation cost; (4)Theoretical teaching and practical teaching can be implemented simultaneously to effectively improve the quality of teaching; (5) Reduce the use of physical environment and laboratory equipment, reduce the maintenance and management costs of teaching experiments; [2] (6) Realize the virtualization, digitization and networking of laboratory resources, promote the open sharing of resources, and solve the problems of redundant construction of educational resources and uneven distribution.

\section{Necessity of Constructing the Virtual Simulation Experiment Teaching Platform of Economics and Management}

The management knowledge has a strong guiding significance for practice. It is the summary and refinement of human economic management activities. It is difficult to let students understand and master a comprehensive knowledge system and professional skills based on abstract knowledge in the classroom. On the other hand, the traditional experimental teaching method makes a series of outstanding problems in the training of management personnel. Although the students have studied through four years of undergraduate study, the knowledge system and professional ability they have built cannot meet the needs of the post. On the other hand, the traditional experimental teaching method makes a series of outstanding problems in the training of management personnel. Although the students have studied through four years of undergraduate study, the knowledge system and professional ability they have built cannot meet the needs of the post. The above reasons lead to the disconnection between the cultivation of students' ability and the social needs of colleges and universities, and students cannot adapt to the needs of their posts [3].

In order to solve the above problems, it is necessary to use advanced virtual simulation technology to create a virtual simulation practice environment and conditions. For professional and practical courses, students can carry out simulation practice in the virtual simulation environment, focusing on training students to solve economic management. The practical ability of the problem allows our graduates to have a panoramic view of the company's management, multiple roles, and immersive hands-on learning experience, laying a solid foundation for future entry into the workplace.

\section{Objectives and Principles of Construction of Virtual Simulation Experiment Teaching Platform}

\subsection{Construction Goal}

Focusing on the fundamental tasks of Lideshu people, adapting to the new requirements of economic and social development for the training of economics and management personnel, and the new rules of education and teaching in the information age, with the core of improving students' practical ability and innovative spirit, relying on modern information technology, with the information content of the experimental teaching urgently needed by the management majors as the direction, based on the complete experimental teaching project, the construction of the virtual simulation experiment teaching platform of the management type will form a professional information system with reasonable professional layout, excellent teaching effect and open sharing. The experimental teaching project demonstrates a new system to support the overall improvement of the quality of the professional management of economics and management[4].

\subsection{Construction Principle}

The following principles should be followed in the construction of the platform: 


\subsubsection{Student-centered experimental teaching philosophy}

Adhere to all needs from the needs of students, pay attention to the comprehensive cultivation of students' sense of social responsibility, innovation, and practical ability, pay attention to the collaborative implementation of knowledge transfer, ability training, and quality improvement, mobilize the enthusiasm and initiative of students to participate in experimental teaching, and stimulate students' Learning interest and potential to enhance students' ability to innovate and create[5].

\subsubsection{Accurate and appropriate experimental teaching content}

Adhere to the demand orientation, closely combine the needs of economic and social development for the management of economic management talents, closely combine the professional characteristics and the latest achievements of industrial development, closely combine the characteristics of school positioning and talent cultivation, adopt modern information technology, and have accurate research and development principles, compact content and length of time. A reasonable and difficult virtual simulation experiment teaching project.

\subsubsection{Advanced and reliable experimental research and development technology}

The research and development of virtual simulation experiment teaching project aims to complete the teaching requirements and content, and comprehensively apply multimedia, big data, 3D modeling, artificial intelligence, human-computer interaction, sensors, supercomputing, virtual reality, augmented reality, cloud computing and other networks. Chemical, digital, and intelligent technical means to improve the attractiveness and effectiveness of experimental teaching programs. Strengthen the research on reliability of related technologies, pay attention to the comprehensive and multi-level protection of students using virtual simulation experiment teaching projects, and effectively protect students' health.

\subsubsection{Stable and safe open operation mode}

Fully consider the operation needs of different regions, different levels and different types of students to access experimental teaching projects, and build an open, expansive, compatible and forward-looking virtual simulation experiment teaching project operation platform.

\section{Thoughts on the Construction of Virtual Simulation Experiment Teaching Platform for Economic Management}

During the "Twelfth Five-Year Plan" period, the ministry of education launched the selection and construction of the National Virtual Simulation Experimental Teaching Center. The first batch of virtual enterprise experimental teaching centers for modern enterprise business operations was selected.

According to the talent training program of Harbin University of Commerce, relying on the national virtual simulation experiment teaching center of our school-the virtual simulation experiment teaching center of modern enterprise business operation, adhere to the guiding ideology of "scientific planning, sharing resources, highlighting key points, improving efficiency and sustainable development”. With the aim of comprehensively improving students' innovative spirit and practical ability, with the core of sharing high-quality experimental teaching resources, and focusing on the construction of information-based experimental teaching resources, the virtual simulation experiment teaching center of modern enterprise business operation is constructed. A cross-professional virtual simulation experiment teaching platform for economics and management.

Our school has set up a compulsory practice course of "Company Creation and Operation" in the three-week period of the school's management major. Through the system simulation of the government, social institutions, departments and positions in the real social environment, students can conduct pre-job internships, so that students can recognize the work content and characteristics of 
different organizations and different positions within the society, and train students to do business management. Comprehensive execution ability, decision-making ability and innovation and entrepreneurial ability to cultivate students' sense of collaboration, team spirit and comprehensive professionalism.

The cross-disciplinary comprehensive internship platform for economics and management is divided into four parts:

\subsection{Self-learning stage}

The enterprise case data will be processed and processed, the business process will be designed, the economic background and cultural environment of the enterprise will be created, and independent learning platforms such as learning websites, case libraries, forums and online courses will be built. Students learn about the business process through self-study, and employ entrepreneurs or well-known alumni to give special lectures to interpret macroeconomic policies and entrepreneurial experiences.

\subsection{The enterprise creates a simulation phase}

Let students understand the whole process of enterprise creation and the connection with external service organizations during the creation process.

\subsection{Simulation stage of enterprise operation and management}

Divide students into different groups, form their own businesses, and serve as CEO, CFO, marketing manager, production manager, and purchasing manager. The whole process simulates a product design, production line planning, production planning, sales management, financial planning, etc. of a manufacturing enterprise. The system not only pays attention to the recurrence of business processes, but also allows students to experience the manufacturing process in the manufacturing process. In this way, students can develop the ability to discover problems, analyze problems and solve problems in a dynamic market environment, and experience the essence of business decision-making and the joy of confrontation.

\subsection{Competition training stage}

This part organizes students to participate in ERP sand table simulation competitions, enterprise management decision-making competitions and other activities, and at the same time, joint relevant departments to carry out vocational skills training to improve employment competitiveness.

The platform successfully solved the problem of difficult internships for economics students. Students can truly experience the whole process of business operations without going out of school. By playing various roles in business management, they can truly experience the hardships of the workplace and the ups and downs of business operations. On the other hand, the platform integrates innovation and entrepreneurship education into the real practical experience, allowing students to truly feel the workplace, gaining experience and improving their ability to gain experience and release their dreams.

\section{Application Effect of Cross-professional Virtual Simulation Experiment Teaching Platform}

Harbin University of Commerce's cross-professional virtual simulation experimental teaching platform has been officially launched since 2009, relying on the national virtual simulation experiment teaching center (modern enterprise business operation virtual simulation experiment teaching center), facing the School of Economics, School of Management, Finance More than 20 undergraduate majors, including colleges, computer colleges, foreign language colleges, and law schools, have successfully conducted more than 45,300 undergraduate students in 96 sessions to participate in the "Company Creation and Operation" comprehensive internship, and completed more than 1,800 entrepreneurial design works. The practical teaching of "company creation and operation" expands students' innovative and entrepreneurial thinking, and trains students' comprehensive quality 
and management ability, which is highly praised by students. The platform also attracted the attention of the news media. The media such as Heilongjiang Daily, Life News, Heilongjiang Morning News, Heilongjiang Satellite TV and China Higher Education Magazine conducted special reports to promote the platform's successful experience and have significant radiation effects at home and abroad.

\section{Acknowledgements}

This work was financially supported by practice teaching reform and research project of Harbin University of commerce (SJXM2017B003) and national undergraduate innovation and entrepreneurship training program (201710240071).

\section{References}

[1] Li Wenlei. Research on virtual simulation platform and experimental teaching system of economics and management [J]. Experimental Technology and Management, 2016, 33 (01): 208-210.

[2] Fu Qiang, Huang Wenbin. Research on Virtual Simulation Practice Teaching of Economic Management [J]. China Modern Educational Equipment, 2016 (03): 62- 64.

[3] Zhang Qin, Mao Zhishan. Exploration on the construction of virtual simulation experiment teaching platform for economic management in applied colleges [J]. Management Observation, 2016 (01): 124-126.

[4] Zheng Shuang, Wu Haidong, Chen Zhaohui. Exploration on the Construction of Virtual Simulation Experiment Teaching Center for Enterprise Economic Activities [J]. Journal of Experimental Technology and Management, 2014, 31(11): 13-16.

[5] Zhang Hongxia, Yang Yuan, Wang Xiangqian. Construction of virtual simulation experiment teaching center of economics and management subject in colleges and universities [J]. High Teaching Journal, 2015 (18):238-239. 